\title{
THE EFFECT OF SUBSTITUTING COCOA AND CONVENTIONAL SUGAR WITH CAROB POWDER AND HONEY RESPECTIVELY ON THE PHYSICOCHEMICAL, RHEOLOGICAL AND SENSORY PROPERTIES OF DARK CHOCOLATE
}

\author{
Deepika Bhardwaj $^{1}$, Baljeet Singh Yadav ${ }^{\circledR}$, Ritika B.Yadav ${ }^{1}$, Nidhi Dangi $^{1}$ \\ ${ }^{1}$ Department of Food Technology \\ Maharshi Dayanand University, Rohtak (Haryana) India-124001 \\ ${ }^{凶}$ baljeetsingh.y@gmail.com \\ $\frac{\text { https://doi.org/10.3 }}{\text { Article history: }}$ \\ Received: \\ 18 October 2020 \\ Accepted: \\ 25 February 2021 \\ Keywords: \\ Dark chocolate; \\ Carob; \\ Honey; \\ Rheology; \\ Sensory attributes.

\begin{abstract}
The effect of replacing cocoa and conventional sugar with carob powder and honey respectively on the physico-chemical, rheological, and sensory properties of dark chocolate was evaluated. The ash content and crude fiber content of the dark chocolate increased significantly $(\mathrm{p} \leq 0.05)$ whereas, total sugar content decreased with the increasing carob but decreasing honey concentration in the formulation. The total phenolic content (TPC) increased nearly four-fold and caffeine content reduced to trace amount $(0.03 \mathrm{mg} / \mathrm{g})$ with $100 \%$ replacement of cocoa with carob. Chocolate melt exhibited a non-Newtonian flow behavior with Casson viscosity ranging from 1.61 to $7.51 \mathrm{~Pa}$.s. The increase in carob content enhanced the storage modulus $\left(\mathrm{G}^{\prime}\right)$ and loss $\left(\mathrm{G}^{\prime \prime}\right)$ modulus with a dominance of elastic nature. Dark chocolate with good acceptable sensory scores, good dark color appearance and with trace amounts of caffeine and high fiber content can be prepared using carob powder and honey as substituent ingredients. The carob, which is relatively underutilized for food applications, although in recent past its application profile in food applications has increased, can be better exploited by the food industry for the development of novel food products like chocolate. The high nutrient profile of carob and its better antioxidant potential in comparison to cocoa can make it a better healthy food ingredient in various types of processed food products.
\end{abstract}

\section{Introduction}

Cocoa is the main ingredient in chocolate manufacture and its value and quality are related to complex flavors and to its distinct sensory properties. Dark chocolate has a more intense cocoa flavour than milk chocolate and this stronger sensory signal may lead to a stronger sensory satiety response. Dark chocolate can have $70-85 \%$ cocoa solids and therefore, flavanol content of dark chocolate is five times more than that of milk chocolate (Katz et al., 2011). The polyphenolic profile of cocoa mainly comprises of catechins (37\%), anthocyanins (3\%) and proanthocyanidins
(58\%) (Lamuela-Raventós et al., 2005). However, chocolate is a common culprit in heart burn as it contains concentrations of theobromine, an alkaloid that is closely related to the caffeine, which relaxes the esophageal sphincter muscle, letting stomach acid squirt up into the esophagus (Murphy et al., 1988). Cocoa also contains tyramine that may trigger migraine headache. Apart from this, high sugar in chocolate may also has various health implications such as blood pressure, heart diseases, and tooth decay, obesity and increased blood glucose and insulin levels. Thus, increasing consumer's demand for the 
caffeine free chocolate with low glycemic index coupled with overwhelming demand of cocoa powder for chocolate manufacturing has increased the quest for suitable substitutes for cocoa and sugar in dark chocolate.

Carob is the fruit of an evergreen tree (Ceratonia siliqua L.) cultivated in the Mediterranean area. The pulp of the carob pod is mainly used for animal feed, but recently its utilization has been reported as a valuable food ingredient (Nasar-Abbas et al., 2016; Goulas et al., 2016). In contrast to cocoa, carob contains relatively very high sugar and fiber content but negligible amounts of theobromine and caffeine. Unlike to that of cocoa polyphenols, the carob polyphenolic compounds are abundant in phenolic acids mainly gallic acid and flavonoids and tannins (Goulas et al., 2016; Papagiannopoulos et al., 2004) contributing to its good antioxidant activities (Nasar-Abbas et al., 2016), anticancer and antiproliferation effects (Saura-Calixto et al., 2010), antidiabetic effect (Bãnuls et al., 2016) and cholesterol lowering effect (Ruiz-Roso et al., 2010). Carob pulp is gaining popularity for its organoleptic properties, aroma, color, and taste, and for its dietary quality as roasting of carob generates cocoa like aroma, enhancing its suitability as cocoa substitute (Ayaz et al., 2009). Therefore, the current trend is to utilize roasted carob powder as a substitue for cocoa powder in different food formulations (Pawłowska et al., 2018; Moreira et al., 2017; Srour et al., 2016; Salem and Fahad, 2012). The implication of using carob in chocolate resides in its caffeine and theobromine free nature (Bengoechea et al., 2008).

The high sugar content of chocolate has adverse health effects particularly for diabetic people and therefore, studies have been focused on substitution of sucrose with other sweetening agents such as tagatose and inulin (Shourideh et al. (2010b), sucralose and maltodextrin (Farzanmehr and Abbasi, 2009), jaggery (Chand et al., 2011), stevia and agave nectar (Vahedi and Mousazadeh, 2016) in chocolate in order to reduce the calorie content or glycemic index of the chocolate. Another, sugar alternate can be honey, which is having low glycemic index and greater health and nutritional properties in comparison to sucrose. Since, rheological properties of chocolate are affected by both formulation and processing conditions (Schantz and Rohm, 2005), it is imperative to study the rheological properties in light of the process design and final product quality. Therefore, keeping in view of the above facts, the present investigation was undertaken to explore the suitability of carob powder and honey as replacement for cocoa and sucrose respectively for dark chocolate making and its quality characterization.

\section{Materials and methods}

Carob powder was purchased from the Urban Platter Food Company, Mumbai (India), Cocoa butter was purchased from Cosmix stores, Telangana (India) and soya lecithin (emulsifier) was purchased from Baskerville India Pvt. Ltd, Madhya Pradesh. Carob powder contained $0.0 \mathrm{~g}$ fat, $4.0 \mathrm{~g}$ protein and $7.0 \mathrm{~g}$ sugar per $15.0 \mathrm{~g}$ as per the specification given. Honey and other ingredients such as cocoa powder and vanilla were purchased from the local market in Rohtak. All the other chemicals and regents used in this study were of analytical grade.

\subsection{Formulation and preparation of dark chocolate}

Dark chocolates were prepared with 30,50 , 70 and $100 \%$ replacement level of cocoa powder with carob powder in the formulation along with varying concentration of honey. The formulations used for the development of final products are as given in the Table (1). The process flow chart for the preparation of dark chocolate is as given in the Fig.1. The developed chocolate samples were stored under refrigeration temperature for 28 days to assess the stability of chocolates with reference to the rancidity and sensory quality attributes. 
Weighing of ingredients

Heating of cocoa butter $\left(40-45^{\circ} \mathrm{C}\right)$

Addition of carob powder/ cocoa powder

Mixing at $\left(50^{\circ} \mathrm{C}\right)$ for $20 \mathrm{~min}$

Cooling to $38^{\circ} \mathrm{C}$ at room temp

Addition of honey, emulsifier and vanilla

Tempering (with temperature profile starting with $32^{\circ} \mathrm{C}$, lowering to $27^{\circ} \mathrm{C}$ and final temperature of $3^{\circ} \mathrm{C}$ to obtain the most stable form of cocoa butter crystals i.e. $\beta \mathrm{V}$ crystals)

Moulding
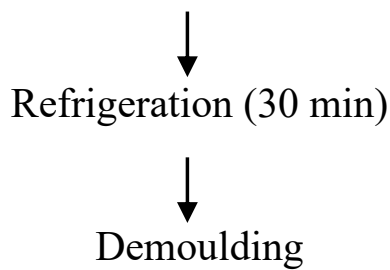

Packing in aluminum foil

Figure 1. The process flow diagram for the preparation of dark chocolate

Table 1. Formulations for the development of dark chocolates

\begin{tabular}{|c|c|c|c|c|c|c|}
\hline Sample & $\begin{array}{c}\text { Cocoa powder } \\
\text { (g) }\end{array}$ & $\begin{array}{c}\text { Carob powder } \\
\text { (g) }\end{array}$ & $\begin{array}{c}\text { Cocoa butter } \\
\text { (g) }\end{array}$ & $\begin{array}{l}\text { Honey } \\
\text { (g) }\end{array}$ & $\begin{array}{c}\text { Vanilla } \\
\text { (g) }\end{array}$ & $\begin{array}{c}\text { Emulsifier } \\
\text { (g) }\end{array}$ \\
\hline $\mathbf{A}$ & 20.0 & - & 20.0 & 13.0 & 0.5 & 1.0 \\
\hline B & 14.0 & 6.0 & 20.0 & 11.5 & 0.5 & 1.0 \\
\hline $\mathbf{C}$ & 10.0 & 10.0 & 20.0 & 9.5 & 0.5 & 1.0 \\
\hline D & 6.0 & 14.0 & 20.0 & 7.0 & 0.5 & 1.0 \\
\hline $\mathbf{E}$ & - & 20.0 & 20.0 & 5.0 & 0.5 & 1.0 \\
\hline
\end{tabular}




\subsection{Chemical composition of dark chocolate}

The moisture, fat, ash, crude fiber and protein and sugar content of the developed chocolate samples were determined using standard AOAC (2000) methods.

\subsubsection{Total phenolic content (TPC)}

TPC was determined by Folin-Ciocalteu assay using gallic acid as standard phenolic acid and the results were calculated as gallic acid equivalent (mg GAE/g) as suggested by the regression equation $(\mathrm{y}=0.0039 \mathrm{x}+0.0406$; $\mathrm{R}^{2}=0.998$ ) derived for the standard curve of gallic acid, where ' $\mathrm{x}$ ' is the concentration and ' $\mathrm{y}$ ' is the absorbance.

\subsubsection{Caffeine content}

Caffeine content of chocolate was determined by UV-VIS spectrometric method (Dobrinas et al., 2013). For the preparation of standard curve, working standard solutions (3, $6,9,12,15$ and $18 \mathrm{mg} \cdot \mathrm{L}^{-1}$ ) were prepared using the standard stock solution $(0.0100 \mathrm{~g}$ of caffeine $/ 100 \mathrm{ml}$ of double distilled water). The caffeine content of the various samples of dark chocolate was measured using the obtained regression equation $\left(\mathrm{y}=0.0222 \mathrm{x}-0.0122 ; \mathrm{R}^{2}=\right.$ $0.9994)$, where ' $x$ ' is the concentration and ' $y$ ' is the absorbance.

\subsection{Rancidity}

Rancidity of the chocolate samples was determined by IS: 7679 - 1978 method. $10.0 \mathrm{~g}$ of chocolate sample was taken and $10 \mathrm{ml}$ of $0.1 \%$ phloroglucin dihydrate solution was added to it. The appearance of pink colour was indicative of rancidity.

\subsection{Color analysis of dark chocolate}

The colour measurement of chocolate samples was carried out using a Hunter Lab Colorimeter (Colour flex EZ). The measurements were made with a D65 illuminant, $25.4 \mathrm{~mm}$ diameter of the measurement hole. The ' $L$ *' scale showed light Vs dark, where a low number (0-50) indicated dark and a high number (51-100) indicated light. The ' $a *$ ' scale showed red vs green, where a positive number indicated red and a negative number indicated green. The ' $b$ *' scale showed yellow vs blue, where a positive number indicated yellow and a negative number indicated blue. The chroma and hue values were determined using the mean of the measured values by different formulas mentioned below

Chroma $(C)=\left(a^{* 2}+b^{* 2}\right) 0.5$ (Giese, 2000)

Brown index $(\mathrm{BI})=\left(100-\mathrm{L}^{*}\right)(\mathrm{Jimoh}$ et al., 2009)

\subsection{Rheological properties of chocolate melt}

The chocolates were placed in container and melted in a hot water bath at $70^{\circ} \mathrm{C}$. Rheological properties of the samples were measured using a dynamic rheometer (MCR 102, Anton Paar GmbH, Germany) with cone and plate geometry $\left(1^{\circ}\right.$ cone angle, $40 \mathrm{~mm}$ diameter and $0.08 \mathrm{~mm}$ gap). For dynamic viscoelastic determinations two different experiments were performed at $37^{\circ} \mathrm{C}$. (1) Deformation sweep at a constant frequency $(10$ $\mathrm{rad} / \mathrm{S}$ ) to determine linear viscoelastic range and (2) Frequency sweep at a constant deformation at $(0.01 \%$ stain $)$ over a frequency range $0.1-100 \mathrm{rad} / \mathrm{s}$. The storage modulus $\left(\mathrm{G}^{\prime}\right)$, loss modulus $\left(\mathrm{G}^{\prime \prime}\right)$ and loss factor $\left(\tan \delta=\mathrm{G}^{\prime \prime} /\right.$ $\left.\mathrm{G}^{\prime}\right)$ as tangent a function of frequency $(\omega)$ were obtained.

Steady flow tests were also performed at $25^{\circ} \mathrm{C}$ to obtain shear rate versus shear stress curves. The cone was programmed to increase the shear rate from $0-300^{\text {s- } 1}$ using the equipment software. The experimented data were fitted to the Casson equation:

Where,

$$
\tau^{1 / 2}=\tau_{\mathrm{o}}^{1 / 2}+\eta_{\mathrm{a}} \varepsilon^{1 / 2}
$$

$$
\begin{aligned}
& \tau_{\mathrm{o}}=\text { Casson yield stress }(\mathrm{Pa}) \\
& \eta_{\mathrm{a}}=\operatorname{Viscosity}(\mathrm{Pa} . \mathrm{s}) \\
& \varepsilon=\operatorname{Shear} \text { rate }\left(\mathrm{s}^{-1}\right) .
\end{aligned}
$$

\subsection{Sensory evaluation}

The sensory analysis was performed on a 9 point hedonic scale by a panel of 15 semitrained members (8 males and 7 females), with an age group between 21 and 25 years (mean 
age: 23 years). Before performing the sensory evaluation, the chocolate samples stored under refrigeration were kept at room temperature for $30 \mathrm{~min}$. The chocolate samples were evaluated for their appearance, taste, color, odour and after taste. The sensory evaluation was done at an interval of 7 days during the storage period of 28 days.

\subsection{Statistical analysis}

The data was analyzed using 'SPSS' statistical software. ANOVA was applied in a completely randomized model. The values were represented as mean \pm S.D. of four independent determinations. The mean was compared at $5 \%$ level of significance.

\section{Results and discussion}

\subsection{Physico-chemical analysis of dark chocolate}

The results of physico-chemical analysis of different samples of dark chocolate are given in Table (2). The moisture content of various dark chocolate samples varied from 5.3-10.0 \% and it was significantly higher than those reported in the literature, which is normally around 1 percent (Tran et al., 2016). This higher moisture content could be due to the use of honey in the formulation and the chocolate samples containing higher concentration of honey had higher moisture content. The fat content ranging from 45.2 to $51.5 \%$ as observed in the present study for different chocolate samples was reasonably in agreement with the reported values of 36.5 to $53.26 \%$ by
Gao et al. (2015) for various dark chocolates. Expectedly, it decreased in the order of $\mathrm{A}>\mathrm{B}>$ $\mathrm{C}>\mathrm{D}>\mathrm{E}$ with the decreasing amount of cocoa. A similar trend of decreasing fat content with the increasing carob concentration in milk chocolates has also been reported by Salem and Fahad (2012). The ash content and crude fiber content of the dark chocolate increased in a highly significant manner $(\mathrm{p} \leq 0.05)$ as with the increasing carob concentration in the chocolate formulation and it increased to a maximum of $5.4 \%$ and $9.2 \%$ respectively when compared to respective values of $1.4 \%$ and $1.9 \%$ in the control sample. The total sugar content of different chocolate samples varied from 13.46 to $24.48 \%$, and it decreased as the concentration of carob powder was increased and honey decreased. Although carob powder is known to contain relatively very high amount of sugars than cocoa powder (Loullis and Pinakoulaki, 2017) but it seems that in the current study, the sugar content was much affected with the addition of honey. However, Salem and Fahad (2012) reported higher values of total sugar content in milk chocolates containing carob. The $\mathrm{pH}$ of different dark chocolate samples ranged from 4.96 to 6.97. Highest $\mathrm{pH}$ was found for sample $\mathrm{A}$ while lowest for sample E. The $\mathrm{pH}$ decreased as the carob concentration was increased. Vahedi and Mousazadeh (2016) reported the $\mathrm{pH}$ for different dark chocolates in the range of 6.94 to 7.0. This decrease in $\mathrm{pH}$ might be due to higher tannin content in carob powder

Table 2. Physico-chemical properties of dark chocolates

\begin{tabular}{|l|c|c|c|c|c|c|c|}
\hline Sample & $\begin{array}{c}\text { Moisture } \\
\mathbf{( \% )}\end{array}$ & $\begin{array}{c}\text { Fat } \\
\mathbf{( \% )}\end{array}$ & $\begin{array}{c}\text { Ash } \\
\mathbf{( \% )}\end{array}$ & $\begin{array}{c}\text { Crude } \\
\text { Fiber } \\
\mathbf{( \% )}\end{array}$ & $\begin{array}{c}\text { Protein } \\
\mathbf{( \% )}\end{array}$ & $\begin{array}{c}\text { Sugar } \\
\text { Content } \\
\mathbf{( \% )}\end{array}$ & \multicolumn{1}{|c|}{ pH } \\
\hline A & $10.0 \pm 0.18^{\mathrm{d}}$ & $51.5 \pm 0.3^{\mathrm{c}}$ & $1.41 \pm 0.1^{\mathrm{a}}$ & $1.93 \pm 0.1^{\mathrm{a}}$ & $4.66 \pm 0.18^{\mathrm{a}}$ & $24.8 \pm 0.2^{\mathrm{d}}$ & $6.97 \pm 0.05^{\mathrm{c}}$ \\
\hline B & $8.01 \pm 0.44^{\mathrm{c}}$ & $50.4 \pm 0.2^{\mathrm{c}}$ & $2.32 \pm 0.1^{\mathrm{b}}$ & $3.70 \pm 0.1^{\mathrm{b}}$ & $4.74 \pm 0.11^{\mathrm{a}}$ & $20.5 \pm 0.2^{\mathrm{c}}$ & $6.86 \pm 0.02^{\mathrm{c}}$ \\
\hline $\mathbf{C}$ & $7.66 \pm 0.25^{\mathrm{c}}$ & $48.3 \pm 0.2^{\mathrm{b}}$ & $3.01 \pm 0.2^{\mathrm{c}}$ & $5.74 \pm 0.1^{\mathrm{c}}$ & $4.79 \pm 0.20^{\mathrm{a}}$ & $18.8 \pm 0.2^{\mathrm{c}}$ & $6.52 \pm 0.11^{\mathrm{bc}}$ \\
\hline D & $6.66 \pm 0.29^{\mathrm{b}}$ & $47.8 \pm 0.2^{\mathrm{b}}$ & $4.10 \pm 0.1^{\mathrm{d}}$ & $7.71 \pm 0.2^{\mathrm{d}}$ & $4.83 \pm 0.22^{\mathrm{a}}$ & $16.3 \pm 0.1^{\mathrm{b}}$ & $6.13 \pm 0.21^{\mathrm{b}}$ \\
\hline E & $5.30 \pm 0.10^{\mathrm{a}}$ & $45.3 \pm 0.2^{\mathrm{a}}$ & $5.43 \pm 0.1^{\mathrm{e}}$ & $9.20 \pm 0.2^{\mathrm{e}}$ & $4.86 \pm 0.25^{\mathrm{a}}$ & $13.5 \pm 0.3^{\mathrm{a}}$ & $4.96 \pm 0.07^{\mathrm{a}}$ \\
\hline
\end{tabular}

Values are mean \pm SD of four independent determinations; Values with the same superscripts in a particular column do not differ significantly $(\mathrm{p}<0.05) \mathbf{A}=100 \%$ Cocoa; $\mathbf{B}=70 \%$ Cocoa and $30 \%$ carob; $\mathbf{C}=50 \%$ Cocoa and $50 \%$ carob; $\mathbf{D}=30 \%$ Cocoa and $70 \%$ Carob; $\mathbf{E}=100 \%$ Carob. 


\subsection{TPC and caffeine content of dark chocolate}

The TPC for different dark chocolate samples is given in Table (3). The results showed that the sample containing higher amount of carob powder had higher TPC and it varied from 5.33 to $23.32 \mathrm{mg} \mathrm{GAE} / \mathrm{g}$ representing nearly four-fold variation. The carob powder in comparison to cocoa is considered as richer in phenolic acids mainly gallic acid as main polyphenolic compounds. The TPC of carob extracts from various varieties/cultivars grown in different geographic regions have been found to contain polyphenolic compounds ranging from 11.6 to $41.3 \mathrm{mg} \mathrm{GAE} / \mathrm{g}$ (Loullis and Pinakoulaki, 2017). Further, the processing operations such as fermentation of cocoa beans and alkalinization of cocoa powders may also greatly affect the polyphenol content in chocolates (Wollgast and Anklam, 2000). The most abundant polyphenols in carob pods are phenolic acids (gallic acid), flavonoids particularly flavonols and isoflavones and tannins (Stavrou et al., 2018). Roasting of carob pulp may also degrade certain phenolic compounds and some polyphenolic compounds may also be released from polymeric compounds enhancing their available and total phenolic content as well as antioxidant activity of roasted carob (Vitali Čepo et al., 2014; Srour etal., 2016). Markis and Kefalas (2004) reported carob powder as a more potential source of antioxidants in comparison to red wines. Thus, it can be suggested that the carob chocolate might be a potential nutraceutical resource considering its high phenolic content. The antioxidant potential of carob flour could also be important in delaying the lipid peroxidation, thus enhancing the product shelf life.

The cocoa free chocolate revealed only trace amount of caffeine $(0.03 \mathrm{mg} / \mathrm{g})$ and it varied up to $3.62 \mathrm{mg} / \mathrm{g}$ in various dark chocolate samples. The results clearly indicated that with the replacement of cocoa with carob powder, the caffeine content of the dark chocolate can be reduced to very less amount and therefore, such type of chocolate can be a boon for the persons for whom very less or caffeine free products have been recommended. Caffeine comes under Methylxanthines, and generally, theobromine is a caffeine metabolite (Stavric, 1988), which is considered as an alkaloid compound that acts as a stimulant. The content of polyphenols and methylxanthines may vary and it depends upon the source of cocoa variety, its cultivation conditions, process parameters during fermentation and drying, and the chocolate making process (Meng et al., 2009).

Table 3. Total phenolic content and caffeine content of dark chocolates

\begin{tabular}{|c|c|c|}
\hline Sample & TPC (mg GAE/g) & Caffeine (mg / g) \\
\hline A & $5.33 \pm 0.08^{\mathrm{a}}$ & $3.62 \pm 0.13^{\mathrm{d}}$ \\
\hline B & $7.30 \pm 0.37^{\mathrm{b}}$ & $2.57 \pm 0.07^{\mathrm{c}}$ \\
\hline C & $15.66 \pm 1.00^{\mathrm{c}}$ & $2.01 \pm 0.08^{\mathrm{b}}$ \\
\hline $\mathbf{D}$ & $19.77 \pm 0.94^{\mathrm{d}}$ & $0.14 \pm 0.04^{\mathrm{a}}$ \\
\hline E & $23.32 \pm 2.65^{\mathrm{e}}$ & $0.03 \pm 0.015^{\mathrm{a}}$ \\
\hline
\end{tabular}

Values are mean \pm SD of four independent determinations

Values with the same superscripts in a particular column do not differ significantly $(\mathrm{p}<0.05)$

$\mathbf{A}=100 \%$ Cocoa $; \mathbf{B}=70 \%$ Cocoa and $30 \%$ carob; $\mathbf{C}=50 \%$ Cocoa and $50 \%$ carob; $\mathbf{D}=30 \%$ Cocoa and $70 \% \mathrm{Carob} ; \mathbf{E}=100 \%$ Carob. 
3.3. Rheological properties of dark chocolate 3.3.1. Steady shear stress rheological properties

The rheological properties play an essential role not only in determining the efficiency of the process such as mixing and flowing of materials but also application of chocolate melt for coating and molding. The steady flow properties of molten dark chocolate samples were determined using Casson model. The values for the Casson parameters for the chocolate samples are given in Table (4) and the steady flow curves of five different molten chocolates are shown in Fig. 2. Casson yield stress is the force required to initiate the flow of molten chocolate. It represents the low shearrate properties of chocolate and is affected by particle-particle interaction (Servais et al., 2004; Afoakwa et al., 2007; Aidoo et al., 2013). The steady shear results showed that yield stress ranged from 10.39 to $13.99(\mathrm{~Pa})$ and it was found that there was an increase in the Casson yield stress with the increasing carob concentration. Carob powder contains a sufficient amount of fibers (Bengoechaea et al., 2008), which would have contributed to the increased viscosity and increased yield stress of the carob containing chocolates. The addition of carob powder is one of the means of increasing solid particles, which being in contact with cocoa butter dominantly interacted with each other yielding to great collisions, friction and resistance, which are required to be broken down to make the chocolate begin to flow (Servais et al., 2004).
The viscosity of molten chocolate decreased as the shear rate was increased (Fig. 1b). The molten chocolate displayed a shearthinning non-Newtonian behavior as its viscosity decreased with the increasing shear rate. This can be explained by the fact that with the increasing shear rate, the disruption of entanglements dominated over the formation of new ones and the particles aligned in the direction of flow leading to a reduction in the viscosity. The Casson viscosity of chocolate melt increased exponentially ranging from 1.61 to 7.51 (Pa.s). The lowest viscosity was found for sample A while highest for sample C. Servais et al. (2002) suggested that chocolate viscosity should be attributed to several factors such as fat content, shape of particles and particle size distribution. The increase in viscosity could be due to the addition of carob powder in the chocolate. The water capturing ability of carob assisted in the increased viscosity of the chocolates. Syafiq et al. (2015) reported an increase in yield stress and viscosity with the addition of xanthan gum and glycerin in chocolates. The authors hypothesized that with water holding ability, the trapped moisture (bound water) acted as sticking agent and agglomerated sugar particles to form gritty clods and the moisture attached on sugar particles directly increased the friction and apparent viscosity (Afoakwa et al., 2007). The flow curves of carob containing chocolates were not linear which could be due the presence of carob particles which might have increased sample roughness and its attrition to the spindle surface.

Table 4. Casson model parameters for dark chocolates

\begin{tabular}{|c|c|c|}
\hline Sample & $\begin{array}{c}\text { Casson yield stress } \\
(\mathbf{P a})\end{array}$ & $\begin{array}{c}\text { Casson viscosity } \\
(\text { Pa.s) }\end{array}$ \\
\hline $\mathbf{A}$ & $10.39 \pm 0.18^{\mathrm{a}}$ & $1.61 \pm 0.23^{\mathrm{a}}$ \\
\hline $\mathbf{B}$ & $10.87 \pm 0.26^{\mathrm{a}}$ & $6.06 \pm 0.17^{\mathrm{b}}$ \\
\hline $\mathbf{C}$ & $11.27 \pm 0.11^{\mathrm{b}}$ & $7.51 \pm 0.28^{\mathrm{c}}$ \\
\hline $\mathbf{D}$ & $11.39 \pm 0.06^{\mathrm{b}}$ & $6.17 \pm 0.14^{\mathrm{b}}$ \\
\hline $\mathbf{E}$ & $13.99 \pm 0.15^{\mathrm{c}}$ & $6.97 \pm 0.21^{\mathrm{c}}$ \\
\hline
\end{tabular}

Values are mean \pm SD of four independent determinations

Values with the same superscripts in a particular column do not differ significantly $(\mathrm{p}<0.05)$

$\mathbf{A}=100 \%$ Cocoa; $\mathbf{B}=70 \%$ Cocoa and 30\% carob; $\mathbf{C}=50 \%$ Cocoa and $50 \%$ carob; $\mathbf{D}=30 \%$ Cocoa and $70 \%$ Carob; $\mathbf{E}=100 \%$ Carob. 

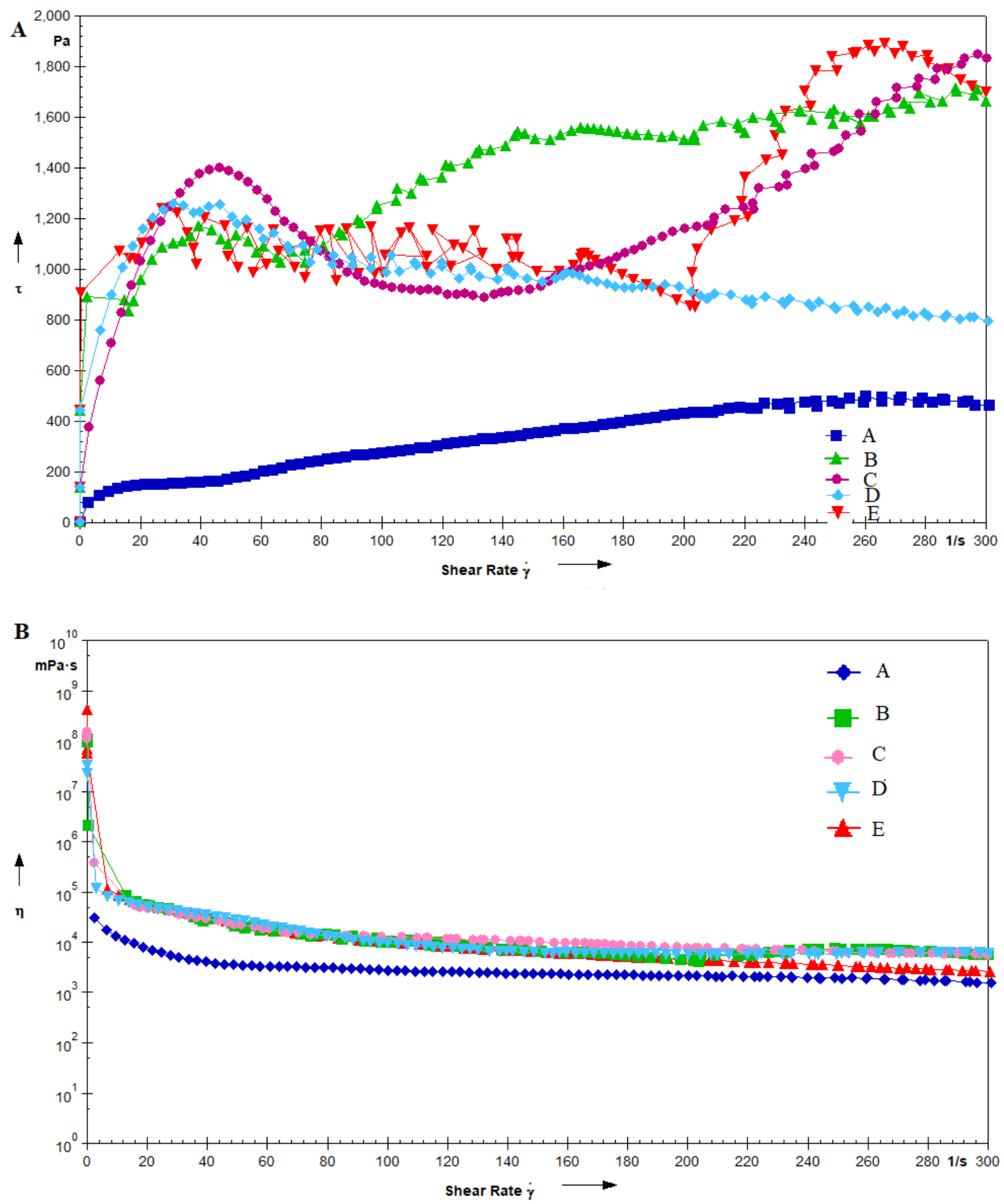

Figure 2. Steady shear rheological properties, (a) flow curve and (b) viscosity curve of dark chocolates.

\subsubsection{Dynamic visco-elastic properties}

The typical curves of dynamic oscillation test data concerning $\mathrm{G}^{\prime}, \mathrm{G}^{\prime \prime}$ and $\tan \delta$ are presented in Fig. 3. $\mathrm{G}^{\prime}$ is the storage modulus expressing the elastic nature and $\mathrm{G}^{\prime \prime}$ is the loss modulus, expressing the viscous nature of the chocolate. All chocolate formulations showed an elastic modulus $\mathrm{G}^{\prime}$, greater than viscous 
modulus $\mathrm{G}^{\prime \prime}$, throughout the measured frequency. These results showed that the chocolate samples had more elastic nature than viscous suggesting that under non-destructive conditions the elasticity had a predominant effect on viscosity (Peressini et al., 2006). The increase in carob content caused a shift in $\mathrm{G}^{\prime}$ and $G^{\prime \prime}$ towards higher values. Both moduli increased with frequency, thus exhibiting a solid like behavior. The increase in $\mathrm{G}^{\prime}$ and $\mathrm{G}^{\prime \prime}$ values in carob chocolates could be due to the addition of carob powder in the chocolates. Carob powder contained fiber rich constituents that might act as strengthening and elastifying agent for the structure which in terms of rheology is closer to a solid material (Spend et al., 2009). Lower values of $\mathrm{G}^{\prime}$ and $\mathrm{G}^{\prime \prime}$ for the sample A might be because of the weakly structured system due to the lubricating and emulsifier effect of fat and lecithin. These results are in agreement with the studies of Johansson and Bergensthål (1992). Similar increase in the $G^{\prime}$ and $G^{\prime \prime}$ values with carob flour addition has also been reported for gluten free breads (Tsatsaragkou and Krokida, 2014).

The loss factor, $\tan \delta=\mathrm{G}^{\prime \prime} / \mathrm{G}^{\prime}$ is a dimension less value that compares the amount of energy lost during a test cycle to the amount of energy stored during the same time. The dynamic mechanical loss tangent $(\tan \delta)$ is shown in Fig. 3 for all the samples. For all samples, $\tan \delta$ values were less than 1 indicating a predominant elastic nature. The values for $\tan \delta$ decreased with a decreasing frequency up to $1 \mathrm{rad} / \mathrm{s}$ after which values fluctuates gently which may be due to the increased relaxation times. The increase in carob content caused a shift in the $\tan \delta$ values towards lower side suggesting that carob addition caused an increase in elasticity of the chocolate. The elastic nature of chocolates is determined by the extent of particle interactions during the recovery of deformed structure and it could be suggested that the presence of fibers in carob powder might have led to increased inter-particle associations in chocolates.

\subsection{Color characteristics of dark chocolates}

Composition and processing parameters are the key factors affecting the color characteristics of chocolate. In the present study, while increasing the level of carob powder, level of honey as a sweetener was decreased. The results obtained from the instrumental color analysis of the chocolate samples are given in Table (5). L* value of approximately 28.54 is considered to be acceptable for dark chocolate as reported by Aidoo et al. (2014). The lower value of $\mathrm{L}^{*}$ indicates a darker appearance. The $\mathrm{L}^{*}$ value ranged from 21.22 to 18.12 , which indicated a good dark color appearance of the chocolate. The highest $\mathrm{L}^{*}$ value was found for the control sample followed by the sample E and C. Sample B and D were comparatively darker in color. Normally, it has been suggested that the chocolate sample containing higher concentration of sugar substitutes represented a darker color (Shah et al., 2010; Aidoo et al., 2014). However, in the present study a consistent trend in the change of color parameters with the changing levels of honey was not obtained. This could be ascribed to the reason that as the level of honey was decreased in the formulation, simultaneously the level of carob powder was increased. The results suggested that there was a possible interaction effect between the sugar rich carob powder and honey during caramelization and maillard reactions to impart the characteristic dark appearance to the chocolate sample, which is evident from the fact that the sample B and D containing reasonably higher concentration of either of the component (carob powder or honey) and lower concentration of other were observed to be darker in color. Positive values of $a^{*}$ and $b^{*}$ indicated the slightly reddish brown color of chocolates. The samples showing lower $\mathrm{L}^{*}$ values also showed higher $\mathrm{a}^{*}$ and $\mathrm{b}^{*}$ values, which indicated their increased dark brown color. The values of chroma which describes the vividness or dullness of a color, ranged from 2.61 to 5.74 with sample B and D having lower values of $L$ showing the higher values of chroma i.e. these chocolates exhibited more brown color with 
higher shine. Similarly, the browning index, which closely associated with the degree of browning on account of maillard browning or caramelization of sugars in chocolate processing, was also higher for the samples B and D.

Table 5. Color characteristics of the freshly prepared dark chocolates

\begin{tabular}{|l|l|l|l|l|l|}
\hline Sample & $\mathbf{L}^{*}$ & $\mathbf{a}^{*}$ & $\mathbf{b}^{*}$ & Chroma & Brown index \\
\hline A & $21.2 \pm 0.2^{\mathrm{b}}$ & $2.97 \pm 0.12^{\mathrm{c}}$ & $1.92 \pm 0.20^{\mathrm{b}}$ & $3.53 \pm 0.11^{\mathrm{c}}$ & $78.8 \pm 0.1^{\mathrm{a}}$ \\
\hline B & $18.1 \pm 0.4^{\mathrm{a}}$ & $3.04 \pm 0.19^{\mathrm{c}}$ & $2.55 \pm 0.26^{\mathrm{c}}$ & $3.96 \pm 0.07^{\mathrm{c}}$ & $81.9 \pm 0.3^{\mathrm{b}}$ \\
\hline C & $20.5 \pm 0.2^{\mathrm{b}}$ & $2.18 \pm 0.24^{\mathrm{b}}$ & $1.45 \pm 0.13^{\mathrm{a}}$ & $2.61 \pm 0.15^{\mathrm{b}}$ & $79.5 \pm 0.1^{\mathrm{a}}$ \\
\hline $\mathbf{D}$ & $18.7 \pm 0.3^{\mathrm{a}}$ & $4.17 \pm 0.14^{\mathrm{d}}$ & $3.95 \pm 0.34^{\mathrm{d}}$ & $5.74 \pm 0.22^{\mathrm{d}}$ & $81.3 \pm 0.2^{\mathrm{b}}$ \\
\hline E & $20.6 \pm 0.1^{\mathrm{b}}$ & $1.74 \pm 0.21^{\mathrm{a}}$ & $1.12 \pm 0.19^{\mathrm{a}}$ & $2.07 \pm 0.19^{\mathrm{a}}$ & $79.4 \pm 0.2^{\mathrm{a}}$ \\
\hline
\end{tabular}

Values are mean \pm SD of four independent determinations

Values with the same superscripts in a particular column do not differ significantly $(\mathrm{p}<0.05)$

$\mathbf{A}=100 \%$ Cocoa; $\mathbf{B}=70 \%$ Cocoa and $30 \%$ carob; $\mathbf{C}=50 \%$ Cocoa and $50 \%$ carob; $\mathbf{D}=30 \%$ Cocoa and $70 \% \mathrm{Carob} ; \mathbf{E}=100 \%$ Carob.

\subsection{Sensory quality characteristics of dark chocolates}

The dark chocolates prepared with substitution of cocoa powder with carob powder are as depicted in Fig 5. The sensory attributes of the chocolate are the most important quality attributes as the consumer enjoys chocolate as a delicacy item for sensory appeal and satisfaction and not as an usual food stuff. The sensory scores for various parameters of the tested dark chocolate samples are depicted in Fig. 4. As indicated, although the sensory scores for most of the parameters generally decreased with the increase in replacement level but still there was no significant difference in most of the sensory parameters of the various freshly prepared cocoa substituted chocolate samples, particularly up to a substitution level of $70 \%$ to that of the control sample. However, in case of complete substitution of cocoa powder with carob powder, the sensory scores for all the parameters except appearance reduced significantly but still in the acceptable range. It was found that the sensory scores for the taste and after taste of the sample E containing $100 \%$ carob powder was slightly bitter in comparison to control sample containing $100 \%$ cocoa powder. This could be ascribed to the presence of higher tannin content in carob powder. Appearance, which is related to the smoothness and brilliance of the surface, is the key sensory attribute of the dark chocolate and this attribute remained most consistent in various samples. Many visual attributes such as shape, gloss, surface smoothness or roughness, haze, translucency and color can contribute to the overall appearance of chocolate (Briones et $a l ., 2006)$. The grayish appearance of the dark chocolate may be caused by fat bloom problem, which is normally observed on account of either the transformation of cocoa butter crystals or the mixing of other fats with cocoa butter while processing the chocolate. Regarding the overall acceptability, the sample C obtained highest score while sample E obtained the lowest score. Interestingly, during storage period of 28 days, there was no significant reduction in the sensory scores for various parameters for different chocolate samples was observed when measured at an interval of 7 days. Only, a slight decrease in sensory attributes of different chocolate samples was observed after the storage of 28 days and sample $\mathrm{C}$ containing $50 \%$ carob powder and $50 \%$ cocoa powder was found to be most acceptable chocolate among all the samples.

Rancid chocolate in its strictest sense i.e. the oxidation of the fats in the cocoa butter, will taste somewhat sharply cheesy and soapy. Results showed that there was no rancidity development during the 28 days of storage period and hence, no off flavors got developed. The higher total phenolic content of the dark chocolate could have been influential in 
delaying the lipid peroxidation (Buzzini et al., 2008).
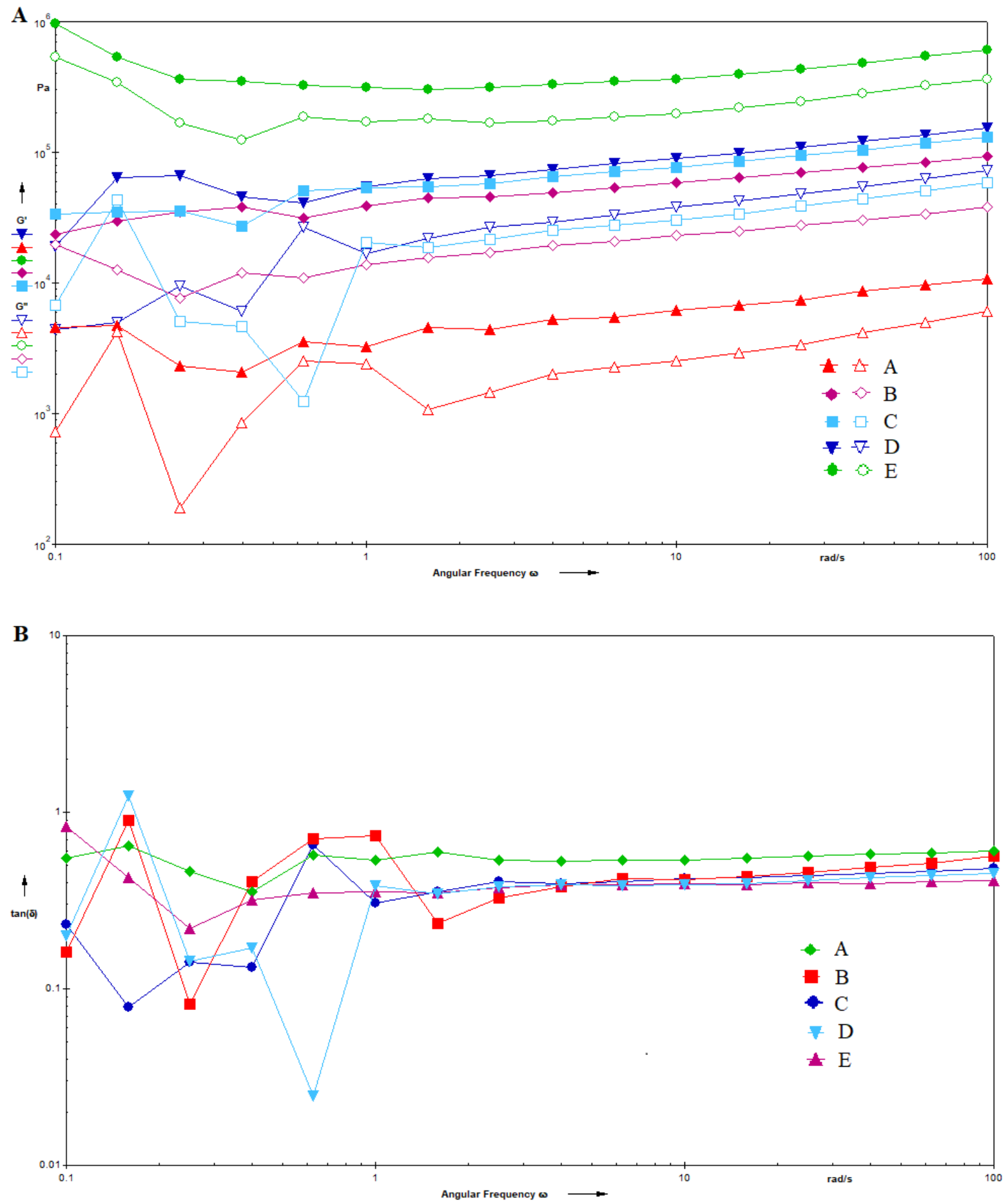

Figure 3. Dynamic rheological properties, (a) frequency sweep spectra and (b) tan $\delta$ of different dark chocolate samples measured at $37^{\circ} \mathrm{C}$. 


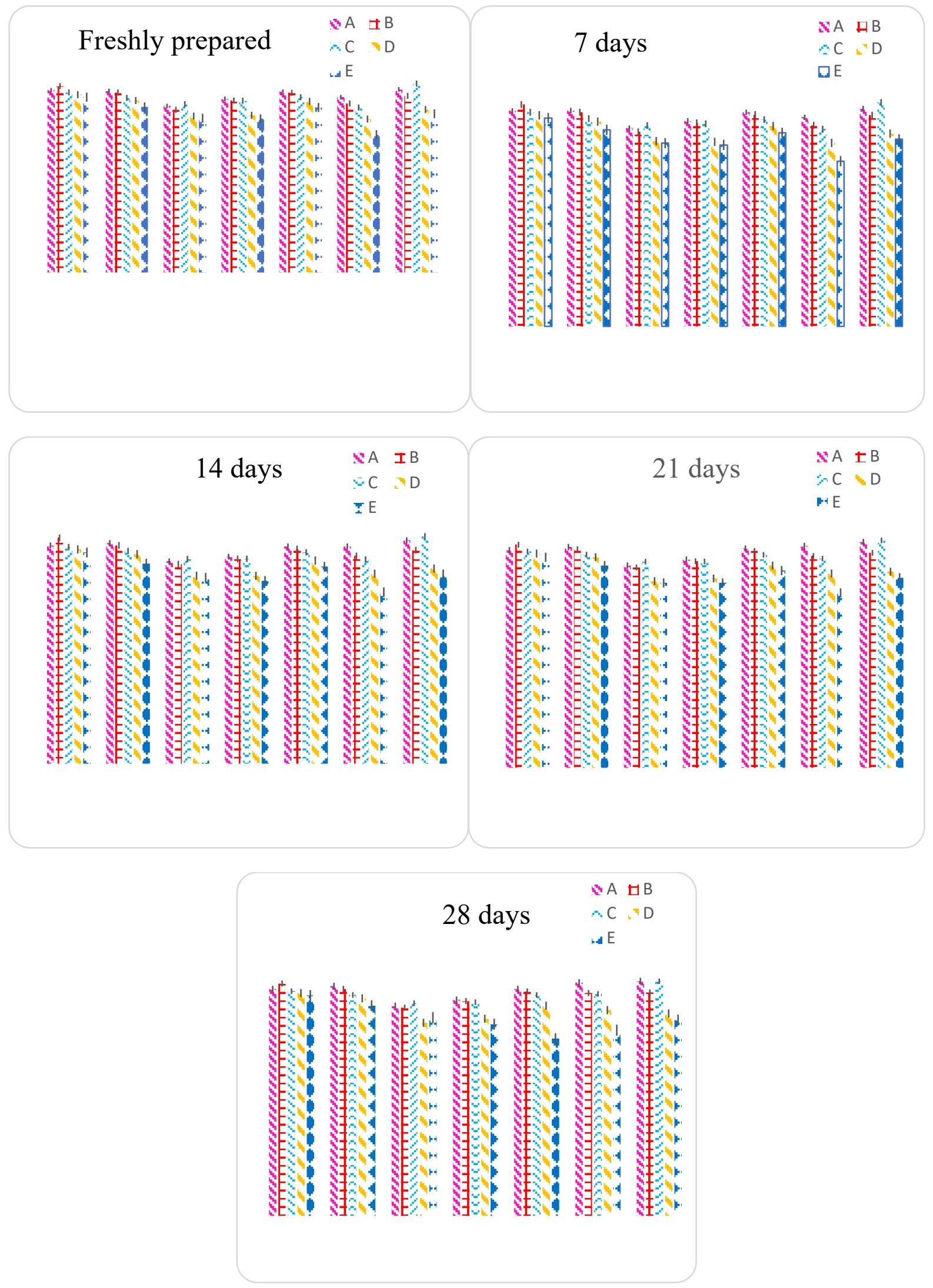

Figure 4. Sensory attributes of different chocolate samples 


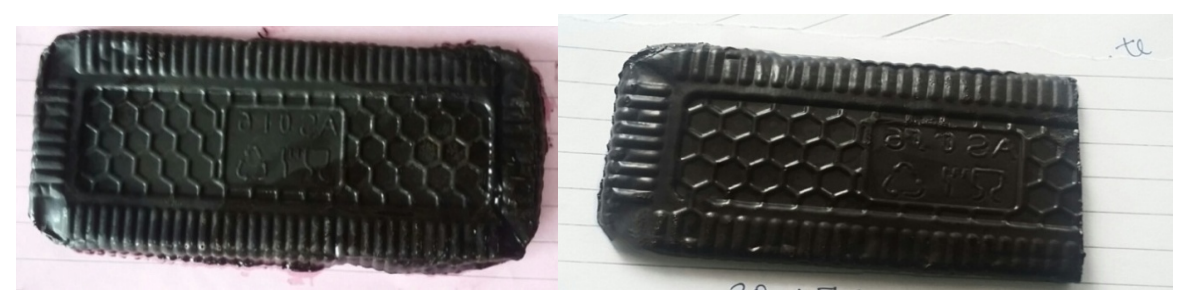

A

B

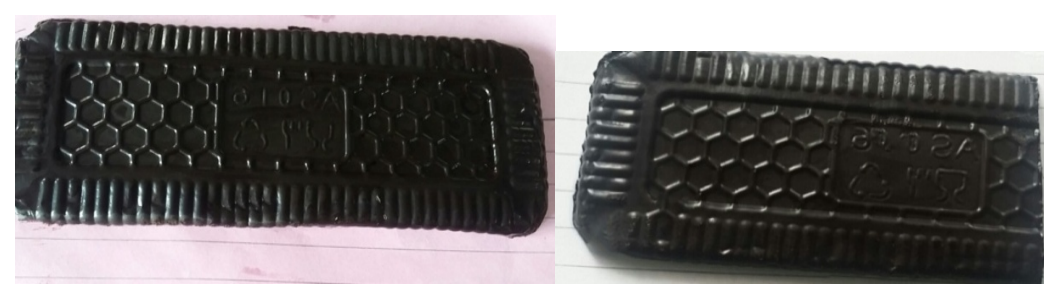

C

D

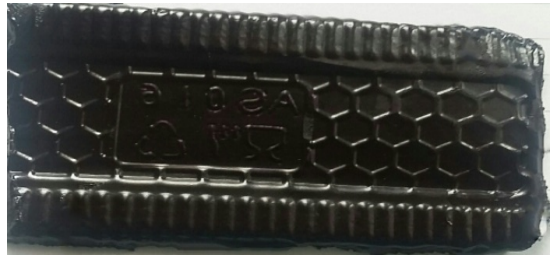

$\mathbf{E}$

Figure 5. Different types of dark chocolates prepared with varying substitution level of cocoa powder with carob powder

\section{Conclusions}

Dark chocolates were prepared with 30,50 , 70 and $100 \%$ replacement level of cocoa powder with carob powder along with varying concentration of honey. The dark chocolate prepared with $100 \%$ replacement of cocoa with carob powder exhibited only trace amounts of caffeine and about four -fold increase in TPC and significantly higher fiber content, which suggested that dark chocolate with added functionality can be produced with carob powder. The addition of carob powder to the formulation increased the Casson yield stress of the dark chocolate melt. The increase in $\mathrm{G}^{\prime}$ and $G^{\prime \prime}$ was observed with the addition of carob powder, which indicated that carob powder acted as elastifying agent attributed to its high fiber content. Good color darkness was attributed to the addition of honey as well as high content of free sugars in carob powder. Sensory attributes like colour, appearance, taste, texture, flavour and overall acceptability scored well and were in acceptable range even after a storage period of 28 days. It can be concluded from the results of the study that good quality dark chocolate with acceptable sensory attributes coupled with added functional attributes like higher amount of TPC and fiber content and negligible amount of caffeine can be produced with partial or complete replacement of the cocoa with carob powder and conventional sugar with honey. 
This type of product can be very beneficial for the persons who prefer caffeine free products.

\section{References}

AOAC. (2000), Official Methods of Analysis $16^{\text {th }}$ ed. Association of Official Analytical Chemists.

Afoakwa, E.O., Paterson, A., Fowler, M. (2007). Factors influencing rheological and textural qualities in chocolate - a review. Trends in Food Science and Technology, 18(6), 290-298.

Aidoo, R. P., Depypere, F., Afoakwa, E. O., Dewettinck, K. (2013). Industrial manufacture of sugar-free chocolates Applicability of alternative sweeteners and carbohydrate polymers as raw materials in product development. Trends in Food Science \& Technology, 32(2), 84-96.

Ayaz, F.A., Glew, R.H., Chuang, L.T., Andrews, R., Torun, H., Duygu Duzgunes, Z., Presely, J.M. (2009). Nutrient content of carob pod (Ceratonia siliqua L.) flour prepared commercially and domestically. Plant Foods for Human Nutrition, 64(4), 86-92.

Bengoechea, C., Romero, A., Villanueva, A., Moreno, G., Alaiz, M., Millan, F., Guerrero, A., Puppo, M. C. (2008). Composition and structure of carob (Ceratonia Siliqua L.) germ proteins. Food chemistry, 107, 675- 683.

Briones, V., Aguilera, J.M., Brown, C. (2006). Effect of surface topography on color and gloss of chocolate samples. Journal of Food Engineering. 77, 776-783.

Buzzini, P., Arapitsas,p., Goretti, M., Branda, E., Turchetti, B., Pinelli, P., Ieri, F., Romani, A. (2008). Antimicrobial and antiviral activity of hydrolysable tannins. Mini Reviews in Medicinal Chemistry, 8, 1179-1187.

Chand, K., Singh, A., Verma, A. K., Lohani, U. C. (2011). Quality evaluation of jaggery chocolate under various storage conditions. Sugar Technology, 13(2), 150.

Dobrinas, S., Soceanu, A., Popescu, V., Stanciu, G., Smalberger, S. (2013).
Optimization of UV-VIS spectrometric method for caffeine analysis in tea, coffee and other beverages. Scientific Study and Research: Chemistry and Chemical Engineering, Biotechnology, Food Industry. 14(2), 071-078.

Farzanmehr, H., Abbasi, S. (2009). Effects of inulin and bulking agents on some physicochemical, textural and sensory properties of milk chocolate. Journal of Texture Studies, 40(5), 536-553.

Gao, X., Guo, T., Han, F., Tian, Y., \& Zhang, Z. (2015). Rheological and sensory properties of four kinds of dark chocolates. American Journal of Analytical Chemistry. 6, 1010-1018.

Giese, J. (2000). Color measurement in Foods as a quality parameter. Food Technology, 54 (2), 98-99.

Goulas, V., Stylos, E., Chatziathanasiadou, M.V., Thomas Mavromoustakos, T., Tzakos, A.G. (2016). Functional components of carob fruit: Linking the chemical and biological space. International Journal of Molecular Sciences, 17(11), 1875.

Jimoh, K.O., Olurin, T.O., Iana, J.O. (2009). Effect of drying methods on rheological characteristics and colour of yam flours. African Journal of Biotechnology, 8(10), 2325-2328.

Johansson, D., Bergenståhl, B. (1992). The influence of food emulsifiers on fat and sugar dispersions in oils. II. Rheology, colloidal forces. Journal of the American Oil Chemists Society, 69(8), 718-727.

Katz, D.L., Doughty, K., Ali, A. (2011). Cocoa and chocolate in human health and disease. Antioxidants and Redox Signaling, 15(10), 2779-2811.

Lamuela-Raventós, R.M., Romero-Pérez, A.I., Andrés-Lacueva, C., Tornero, A. (2005). Review: health effects of cocoa flavonoids. Food Science and Technology International, 11(3), 159-176.

Loullis, A., Pinakoulaki, E. (2018). Carob as cocoa substitute: a review on composition, health benefits and food applications. 
European Food Research and Technology, 244(6), 959-977

Markis, D. P., Kefalas, P. (2004). Carob pods (Ceratonia siliqua L.) as a source of polyphenolic antioxydants. Food Technology and Biotechnology, 42(2), 105108.

Meng, C. C., Jalil, A. M. M., Ismail, A. (2009). Phenolic and theobromine contents of commercial dark, milk and white chocolates on the Malaysian market. Molecules, 14(1), 200-209.

Moreira, T.C., Transfeld da Silva, A., C. Fagundes, S.M.R. Ferreira, L.M.B. Pass os, C. M., Krüger, C.C.H. (2017). Elaboration of yogurt with reduced level of lactose added of carob (Ceratonia siliqua L.). LWT - Food Science and Technology, 76, 326-329.

Murphy, J.M., Pagano, M.E., Nachmani, J., Sperling, P., Kane, S., Kleinman, R.E. (1988). Archives of Pediatric and Adolescent Medicine, 152, 899-907.

Nasar-Abbas, S.M., Huma, Z. E., Vu, T.H., Khan, M.K., Esbenshade, H., Jayasena V. (2016). Carob kibble: a bioactive-rich food ingredient. Comprehensive Reviews in Food Science and Food Safety, 15 (1), 63-72.

Papagiannopoulos, M., Wollseifen, H. R., Mellenthin, A., Haber, B., Galensa, R. (2004). Identification and quantification of polyphenols in Carob fruits (Ceratonia siliqua L.) and derived products by HPLCUV-ESI/MSn. Journal of Agricultural and Food Chemistry, 52(12), 3784-3791

Peressini, D., Bravin, B., Lapasin, R., Sensidoni, A. (2006). Rheological characterization of cocoa creams. In Fisher, P., Erni, P. \& Windhab, E. (Eds.) "Proceedings of the 4th International Symposium on Food Rheology and Structure", September 12-14, 2006, Zurich, Switzerland.

Ruiz-Roso, B., Quintela, J.C., de la Fuente, E., Haya, J., Pérez-Olleros, L. (2010). Insoluble carob fiber rich in polyphenols lowers total and LDL cholesterol in hypercholesterolemic subjects. Plant Foods for Human Nutrition, 65 (1), 50-56.

Salem, E.M., Fahad, A.O. (2012). Substituting of cacao by carob pod powder in milk chocolate manufacturing. Australian Journal of Basic and Applied Science, 6(3), 572-578.

Saura-Calixto, F., Pérez-Jiménez, J., Goñi, I. (2010). Dietary fiber and associated antioxidants in fruit and vegetables. In dela Rosa , L.A., Alvarez-Parrilla, E., \& González-Aguilar, G.A. (Ed), Fruit and Vegetable Phytochemicals: Chemistry, Nutritional Value and Stability, Blackwell Publishing, pp. 223-234..

Schantz, B., Rohm, H. (2005). Influence of lecithin-PGPR blends on the rheological properties of chocolate. LWT Food Science and Technology, 38, 41-45.

Servais, C., Jones, R., Roberts, I. (2002). The influence of particle size distribution on the processing of food. Journal of food engineering, 51(3), 201-208.

Servais, C., Ranc, H., Roberts, I.D. (2004). Determination of chocolate viscosity. Journal of Texture Studies, 34, 467-497.

Shah, A. B., Jones, G. P., Vasiljevic, T. (2010). Sucrose-free chocolate sweetened with Stevia rebaudiana extract and containing different bulking agents-effects on physicochemical and sensory properties. International Journal of Food Science \& Technology, 45(7), 1426-1435.

Shourideh, M. Taslimi, A. Azizi, M. Mohammadifar, M., Mashayekh, M. (2010b). Effects of D-Tagatose, inulin and stevia as sugar substitutes on the physical, chemical, rheological and sensory properties of dark chocolate. Iranian Journal of Nutrition Sciences and Food Technology, 5(3), 29-38.

Srour, N., Daroub, H., Toufeili, I., \& Olabi, A. (2016). Developing a carob-based milk beverage using different varieties of carob pods and two roasting treatments and assessing their effect on quality characteristics. Journal of the Science of Food and Agriculture, 96(9), 3047-3057. 
Stavric, B. (1988). Methylxanthines: toxicity to humans. 2. Caffeine. Food and Chemical Toxicology, 26(7), 645-662.

Stavrou, I.J., Christou, A., KapnissiChristodoulou, C. P. (2018). Polyphenols in carobs: A review on their composition, antioxidant capacity and cytotoxic effects, and health impact. Food Chemistry, 269, 355-374.

Syafiq, A., Amir, I. Z., Sharon, W. X. R. (2014). Mixture experiment on rheological properties of dark chocolate as influenced by cocoa butter substitution with xanthan gum/corn starch/ glycerin blends. International Food Research Journal, 21(5), 1887-1892.

Tran, P. D., Van Durme, J., Van de Walle, D., de Winne, A., Delbaere, C., de Clercq, N., Phan, T. T. Q., Phuc Nguyen, C. H., Tran, D. N., Dewettinck, K. (2016). Quality Attributes of Dark Chocolate Produced from Vietnamese Cocoa Liquors. Journal of Food Quality, 39, 311-322.

Tsatsaragkou,K., Yiannopoulos,S., Kontogiorgi , A., Poulli, E., Krokida, M., Mandala, I. (2014). Effect of Carob Flour Addition on the Rheological Properties of Gluten-Free Breads. Food and Bioprocess Technology, 7(3), 868-876.

Vahedi, H., Mousazadeh, M. (2016). The effect of using stevia and agave nectar as a substitute for sucrose on physical, chemical, rheological and sensory properties of dark chocolate. Der Pharmacia Lettre, 8(15), 194-201.

Vitali Čepo, D., Mornar, A., Nigović, B., Kremer, D., Radanović, D., Vedrina Dragojević, I. (2014). Optimization of roasting conditions as an useful approach for increasing antioxidant activity of carob powder. LWT - Food Science and Technology, 58(2), 578-586.
Wollgast, J., Aklam, E. (2000). Review on polyphenols in Theobroma cacao: changes in composition during the manufacture of chocolate and methodology for identification and quantification. Food Research International, 33, 423-447. 